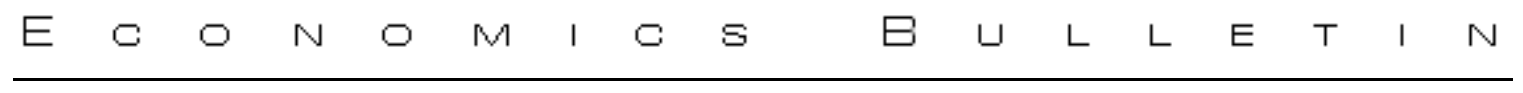

\title{
Growth and labor supply in the presence of habit formation in consumption
}

\author{
Joao Ricardo Faria \\ School of Social Sciences, University of Texas at Dallas
}

\begin{abstract}
This paper examines a model with habit formation in consumption. The model leads to higher equilibrium values in consumption, output, capital accumulation and labor supply than the neoclassical growth model with elastic labor supply. Comparative static analysis shows that an increase in the importance of consumption in the recent past in habit formation is associated with a decrease in growth and labor supply. On the other hand, an increase of the importance of habit stock relatively to present consumption, is found to stimulate growth and labor supply.
\end{abstract}

I would like to thank, without implicating, Nadima El-Hassan and Miguel Leon-Ledesma for useful comments

Citation: Faria, Joao Ricardo, (2002) "Growth and labor supply in the presence of habit formation in consumption." Economics Bulletin, Vol. 4, No. 5 pp. 1-5

Submitted: January 25, 2002. Accepted: February 25, 2002.

URL: http://www.economicsbulletin.com/2002/volume4/EB-02D10002A.pdf 


\section{Introduction}

The hypothesis of habit formation in consumption, introduced by Duesenberry (1949), has gained some strength in the literature because it "fits the data" better than time-separable utility models. It has been particularly useful to explain some problems such as the equity premium puzzle in asset-pricing models [e.g. Constantinides, 1990], and has been applied in many issues such as endogenous growth models [Carroll et al, 2000], rational addiction [Becker and Murphy, 1988], cyclical consumption [Dockner and Feichtinger, 1993], aggregate savings [Alessie and Lusardi, 1997], money and growth [Faria, 2001], and monetary policy [Fuhrer, 2000], to mention a few.

The main idea of habit formation is that consumers' current utility is affected by current consumption relative to a "habit stock" determined by past consumption. Basically, it is assumed that consumers wish to smooth both the level and the change in consumption. Thus, for any given shock in the variables that may influence consumption, both the level and the change in consumption will respond gradually. This behavior differs from the typical jumping response of consumption in the permanent income model with rational expectations [Hall, 1978].

This paper considers the hypothesis of habit persistence in consumption in a standard neoclassical growth model with elastic supply of labor. Previous work in habit formation and growth [e.g. Boyer, 1978] typically assumes inelastic labor supply. Therefore, the model allows us to study the impact of consumption habits on capital accumulation and labor supply. The differences between this model and the traditional neoclassical model highlight the importance of habit persistence and its implications for capital accumulation and labor supply.

\section{The Model}

Consider the problem of an individual who cares about consumption (c) relative to "habit stock" $(h)$ determined by past consumption. The consumer also supplies labor (l), which provides disutility. The instantaneous utility function proposed by Abel (1990) is adapted here to include an elastic supply of labor [e.g. Hansen and Wright, 1992]:

$$
U(c, h, l)=\frac{\left[\left(c / h^{\gamma}\right)\right]^{1-\sigma}}{1-\sigma}-B \log l
$$

where $\sigma$ is the coefficient of relative risk aversion [it is assumed that $\sigma>1$ ], $B$ is a positive parameter, and $\gamma \in[0,1]$ indexes the importance of habits. If $\gamma=0$, then habit stock has no relevance, only the absolute level of consumption is important, and the utility function reduces to the neoclassical case. While if $\gamma=1$, consumption relative to habit stock is all that matters. For values of $\gamma \in(0,1)$, both the absolute and the relative levels are important.

Following Carrol et al (2000) it is assumed that the stock of habits is a weighted average of past consumption. The stock of habits evolves according to:

$$
\dot{h}=\rho(c-h)
$$


where $\rho$ being a positive parameter determining the relative weights of consumption at different times. The larger is $\rho$, the more important is consumption in the recent past. We assume $\rho \in[0,1)$.

The representative agent budget constraint is given by:

$$
\dot{k}=F(k, l)-c
$$

where $F(k, l)$ is a well-behaved neoclassical production function.

The individual maximizes a discounted, infinite stream of utility:

$$
\operatorname{Max}_{c, l} \int_{0}^{\infty} U(c, h, l) e^{-\theta t} d t
$$

subject to equations (2), (3), where $\theta$ is the rate of time preference.

The current value Hamiltonian is:

$$
H=\frac{\left[\left(c / h^{\gamma}\right)\right]^{1-\sigma}}{1-\sigma}-B \log l+\mu[F(k, l)-c]+\lambda \rho(c-h)
$$

where $\mu$ is the costate variable associated with capital and $\lambda$ is the costate variable associated with consumption habits. It is important to notice that when $\rho=0$ and $\gamma=0$, the model collapses to the neoclassical model with elastic labor supply.

The steady state solutions of this model, denoted by an asterisk, are the following:

$$
\begin{aligned}
& F_{k}\left(k^{*}, l^{*}\right)=\theta \\
& c^{*}=F\left(k^{*}, l^{*}\right) \\
& c^{*}=h^{*} \\
& F_{l}\left(k^{*}, l^{*}\right)=\left(\mu^{*} l^{*}\right)^{-1} B \\
& \mu^{*}=\left(c^{*} / h^{* \gamma}\right)^{-\sigma} h^{*-\gamma}+\lambda * \rho \\
& -\gamma c^{*} h^{*-\gamma-1}\left(c^{*} / h^{* \gamma}\right)^{-\sigma}=\lambda *(\rho+\theta)
\end{aligned}
$$

The system of equations (5) to (10) is simultaneous and determine the equilibrium value of capital, $k^{*}$, labor, $l^{*}$, consumption, $\mathrm{c}^{*}$, habit stock, $h^{*}$, and both co-state variables $\lambda^{*}$ and $\mu^{*}$. Notice, however, that by considering a Cobb-Douglas production function: $F(k, l)=k^{a} l^{1-a}$, one can disentangle this system and find out explicit solutions for the endogenous variables. In this case, the optimal consumption $\left(c^{*}\right)$ is given by:

$$
c^{*}=\left\{B(1-a)^{-1}\left[1-\frac{\rho}{\theta+\rho} \gamma\right]^{-1}\right\}^{\frac{1}{(1-\sigma)(1-\gamma)}}
$$

given $c^{*}$, one can find the optimal capital stock $\left(k^{*}\right)$ through the following expression:

$$
k^{*}=\frac{a}{\theta} c^{*}
$$

Finally, given the values of $k^{*}$ and $c^{*}$, one can find the equilibrium value of $l^{*}$ :

$$
c^{*}=k^{* a} l * 1-a
$$

Equations (11)-(13) are the core of this paper. It is easy to see that $k^{*}$ and $l^{*}$ are positively related to $c^{*}$, this makes the comparative statics exercise easier.

First, let us compare this model with the baseline neoclassical growth model with elastic labor supply (denoted by the subscript $N$ ), that is, when $\rho=0$ and $\gamma=0$ : 


$$
c_{N}=\left\{B(1-a)^{-1}\right\}^{\frac{1}{(1-\sigma)}}
$$

One can see that $c_{N}<c^{*}$, and as consequence, $k_{N}<k^{*}$, and $l_{N}<l^{*}$. That is, the modified model with habit persistance leads to higher equilibrium values of consumption, output, capital accumulation and labor supply than the neoclassical growth model.

In order to assess the impact of habit formation in consumption over capital accumulation and labor, we have to study the impact of $\rho$ and $\gamma$ on $c^{*}$ :

$$
\begin{aligned}
& \frac{d c^{*}}{d \rho}=\frac{\theta \gamma}{(\theta+\gamma)(\theta+\gamma+\rho \gamma)(1-\gamma)(1-\sigma)}<0 \\
& \frac{d c^{*}}{d \gamma}=\frac{c^{*}\left[\frac{\rho}{\theta+\gamma+\rho \gamma}+(1-\sigma) \log c^{*}\right]}{(1-\sigma)(1-\gamma)}>0
\end{aligned}
$$

By equation (14), when the consumption in the recent past becomes more important in the formation of consumption habits, through an increase in $\rho$, the present optimal consumption decreases. By equation (15), when the importance of habit stock increases vis-à-vis present consumption, captured by an increase in $\gamma$, the optimal actual consumption increases as well.

The impact of $\rho$ on capital accumulation and labor supply is the following:

$$
\begin{gathered}
\frac{d k^{*}}{d \rho}=\frac{a}{\theta} \frac{d c^{*}}{d \rho}<0 \\
\frac{d l^{*}}{d \rho}=\frac{l^{*}}{(1-a)} \frac{d c^{*}}{d \rho}\left[\frac{1}{c^{*}}-\frac{a^{2}}{\theta k^{*}}\right]<0
\end{gathered}
$$

that is, an increase in the importance of consumption in the recent past in habit formation leads to a decrease in capital accumulation and labor supply.

Finally, the impact of $\gamma$ on capital accumulation and labor supply is given by:

$$
\begin{gathered}
\frac{d k^{*}}{d \gamma}=\frac{a}{\theta} \frac{d c^{*}}{d \gamma}>0 \\
\frac{d l^{*}}{d \gamma}=\frac{l^{*}}{(1-a)} \frac{d c^{*}}{d \gamma}\left[\frac{1}{c^{*}}-\frac{a^{2}}{\theta k^{*}}\right]>0
\end{gathered}
$$

An increase of the importance of habit stock in the utility function fosters capital accumulation and labor supply.

\section{Concluding Remarks}

This article has examined a version of the neoclassical growth model with elastic labor supply modified with the inclusion of habit formation in consumption. The literature captures habit formation in consumption through two parameters. The first appears in the utility function and gives the relative importance of the stock of habits visà-vis present consumption. The second parameter is related to the relative weight of consumption at different times in the formation of habits.

This paper has shown that the model with habit persistance leads to higher equilibrium values of consumption, output, capital accumulation and labor supply than the baseline neoclassical growth model. Comparative static analysis shows that an 
increase in the importance of consumption in the recent past in habit formation is associated with a decrease in capital accumulation and labor supply. On the other hand, an increase of the importance of habit stock relatively to present consumption stimulates capital accumulation and labor supply.

\section{References}

Abel, A.B. (1990) Asset prices under habit formation and catching up with the joneses, American Economic Review Papers and Proceedings 80, 38-42.

Alessie, R. and A. Lusardi (1997) Consumption, saving and habit formation, Economics Letters 55, 103-108.

Becker, G.S. and K.M. Murphy (1998) A theory of rational addiction, Journal of Political Economy 96, 675-700.

Boyer, M. (1978) A habit forming optimal growth model, International Economic Review 19, 585-609.

Carroll, C.D., J. Overland, and D.N. Weil (2000) Saving and growth with habit formation, American Economic Review 90, 341-355.

Constantinides, G.M. (1990) Habit formation: A resolution of the equity premium puzzle, Journal of Political Economy 98, 519-543.

Dockner, E.J. and G. Feichtinger (1993) Cyclical consumption patterns and rational addiction, American Economic Review 83, 256-263.

Duesenberry, J.S. (1967,[1949]) Income, Saving and the Theory of Consumer Behavior, Oxford University Press, New York.

Faria, J.R. (2001) Habit formation in a monetary growth model, Economics Letters 73, 51-55.

Hansen, G.D. and R. Wright (1992) The labor market in real business cycle theory, Federal Reserve Bank of Minneapolis Quarterly Review, Spring, reproduced in P.J. Miller (ed.) The Rational Expectations Revolution, MIT Press, 1994, pp.335-353.

Fuhrer, J.C. (2000) Habit formation in consumption and its implications for monetarypolicy models, American Economic Review 90, 367-390.

Hall, R.E. (1978) Stochastic implications of the life-cycle/permanent income hypothesis: Theory and evidence, Journal of Political Economy 86, 971-987. 